\title{
Abordando a violência contra a mulher em um centro de educação continuada no Triângulo Mineiro
}

Hiêza Laura Pena ${ }^{1}$, Lívia Alves Borges ${ }^{2}$, Ana Luiza de Freitas ${ }^{3}$, Guilherme Maia e Silva ${ }^{4}$, Carla Denari Giuliani ${ }^{5}$

\begin{abstract}
Resumo
Este texto aborda a violência de gênero, seus tipos, sinais de vulnerabilidade e formas de enfrentamento em um espaço educacional, alcançando, principalmente, mulheres em situação de violência. Trata-se de um relato de experiência sobre uma pesquisa observacional, tendo sua relevância na oportunidade de discussão acerca da violência. Entende-se que disponibilizar espaços de fala para que as pessoas se identifiquem em seus comportamentos frente à violência é de extrema importância. As discussões surgiram a partir do tema "Violência de gênero: implicações futuras", com usuários do Centro Educacional de Educação Continuada (CESEC), em uma cidade do Triângulo Mineiro. Por meio da exposição de acontecimentos vivenciados pelos envolvidos e, após a ação realizada, ficou evidente a necessidade da transmissão de conhecimento sobre o assunto para esse público alvo com intuito de criar a habilidade de reconhecer situações de violência e suas formas de denúncia. Concluise que a violência contra a mulher acarreta em sentimentos negativos como humilhação e culpa. A naturalização desse processo dificulta o enfrentamento de tais cenários violentos, demonstrando o quanto a violência é velada em nosso meio.
\end{abstract}

\section{Palavras-chave}

Estudantes. Iniquidade de gênero. Maus-tratos conjugais. Violência de gênero.

\footnotetext{
1 Graduanda em Enfermagem na Universidade Federal de Uberlândia, Minas Gerais, Brasil. E-mail: hieza_laura@hotmail.com.

2 Graduanda em Enfermagem na Universidade Federal de Uberlândia, Minas Gerais, Brasil. E-mail: livia.alves.borges@hotmail.com.

3 Graduanda em Enfermagem na Universidade Federal de Uberlândia, Minas Gerais, Brasil. E-mail: freitassnalu@gmail.com.

4 Graduando em Enfermagem na Universidade Federal de Uberlândia, Minas Gerais, Brasil E-mail: guilherme.m.s.96@hotmail.com.

${ }^{5}$ Doutora em História pela Universidade Federal de Uberlândia, Minas Gerais, Brasil; professora associada 1 da Faculdade de Medicina na mesma instituição. E-mail: denari.carla013@gmail.com.
} 


\title{
Addressing violence against women at a continued education center of Triângulo Mineiro, State of Minas Gerais, Brazil
}

Hiêza Laura Pena ${ }^{6}$, Lívia Alves Borges ${ }^{7}$, Ana Luiza de Freitas ${ }^{8}$, Guilherme Maia e Silva ${ }^{9}$, Carla Denari Giuliani ${ }^{10}$

\begin{abstract}
This text aims to promote a reflection on gender violence, its types, signs of vulnerability and ways of coping in an educational space, reaching mainly women in situations of violence. It's an experience report on an observational research, having its relevance in the opportunity to discuss violence, providing reflections for the empowerment of this people, in order to have reflections on their lives and society. Making speech spaces available for people to identify themselves in their behavior in face of violence is extremely important. The discussions arose from the theme "Gender violence: implications for the future", with users of the Educational Center for Continuing Education (CESEC), in the city from Triângulo Mineiro, State of Minas Gerais, Brazil. Through the exposure of events passed by those involved and, after the action was taken, the need to transmit knowledge on the subject to this target audience became evident in order to recognize situations of violence and their forms of denunciation. it is concluded that violence against women leads to negative feelings such as humiliation and guilt. The naturalization of this process makes it difficult to face such violent scenarios, demonstrating how much the violence is veiled in our environment.
\end{abstract}

\section{Keywords}

Students. Gender inequality. Spouse abuse. Gender-based violence.

\footnotetext{
6 Undergraduate student in Nursing, Federal University of Uberlândia, State of Minas Gerais, Brazil. E-mail: hieza_laura@hotmail.com.

${ }^{7}$ Undergraduate student in Nursing, Federal University of Uberlândia, State of Minas Gerais, Brazil. E-mail: livia.alves.borges@hotmail.com.

${ }^{8}$ Undergraduate student in Nursing, Federal University of Uberlândia, State of Minas Gerais, Brazil. E-mail: freitassnalu@gmail.com.

${ }^{9}$ Undergraduate student in Nursing, Federal University of Uberlândia, State of Minas Gerais, Brazil. E-mail: guilherme.m.s.96@hotmail.com.

${ }^{10} \mathrm{PhD}$ in History, Federal University of Uberlândia, State of Minas Gerais, Brazil; associate professor 1 of the Faculty of Medicine at the same institution. E-mail: denari.carla013@gmail.com.
} 


\section{Introdução}

Ao longo da história, a imagem do feminino esteve ligada a ambiguidades. Os homens, aqueles a quem cabiam os relatos à posteridade, expressavam seus sentimentos e opiniões de forma dupla, ora demonstrando amor e admiração às mulheres, ora demonstrando ódio e repulsa. O olhar masculino reservava às mulheres imagens diferentes, sendo, em determinados momentos, a imagem de um ser frágil, vitimizado e santo, e, em outros, a de força, dissimulada e pecadora.

Já que uma realidade construída é conjugada com a sociedade em que se está inserido, em dada cultura produzem-se e reproduzem-se, por exemplo, os tabus. É desse modo que o ser humano, imerso em códigos culturais particulares, está sujeito a refletir comportamentos em função de interpretações sobre o que é conveniente fazer, dizer ou tocar (ZANATTA; FARIA, 2018).

Levando em consideração que o Brasil foi colonizado por ocidentais, pode-se concluir que os homens no país reproduziram os mesmos conceitos assistidos nos colonizadores em relação à mulher. Assim, desde o período colonial, a exigência de submissão, recato e docilidade foi imposta às mulheres. Essas exigências levaram à formação de um estereótipo que relegava o sexo feminino ao âmbito do lar, no qual sua tarefa seria cuidar da casa, dos filhos e do marido, sendo sempre totalmente submissa a ele, configurando-se o patriarcado, que tem como figura central o homem. Apesar das eventuais mudanças socioculturais ocasionadas pela miscigenação de povos, surgimentos de novos países, desenvolvimento tecnológico e a própria evolução humana como ser social, o patriarcado sobreviveu, com menos evidência, mas herdando muitas características desiguais (ZANATTA; FARIA, 2018).

É perceptível, assim, que a desigualdade entre os gêneros se torne a base das violências sofridas pelas mulheres, pelo simples fato de serem mulheres, o que acontece no espaço público ou privado, sendo nesse último em maior proporção (PIEROTTI; D'OLIVEIRA; TERRA, 2018). O "gênero tanto é um elemento constitutivo das relações sociais fundadas sobre as diferenças percebidas entre os sexos, quanto uma maneira primária de significar relações de poder" (SCOTT, 1995, p. 86), ou seja, a desigualdade de gênero está diretamente ligada às relações de poder.

A violência contra a mulher ocorre devido a fatores culturais, políticos e religiosos construídos socialmente, com base nas diferenças entre os sexos. Essa construção justifica a ideia solidificada de domínio do homem sobre a mulher (NÓBREGA et al., 2019). A Organização Mundial da Saúde (OMS) aponta quase 35\% da população mundial feminina 
sofre violência física e/ou sexual, sendo os agressores, em sua maioria, seus parceiros (OMS, 2013 apud MAFIOLETTI et al., 2018).

Os vários tipos de violência são uma violação clara dos direitos humanos dessas mulheres, que têm sua vida desrespeitada. A forma de identificar e contextualizar determinadas violências muitas vezes é falha, o que dificulta o apoio àquelas em cenário hostil (MEDINA; PENNA, 2008). É de suma importância que tanto a mulher em situação de violência, quanto o profissional de saúde tenham conhecimento e capacidade para reconhecer o ambiente opressor, levando em consideração que, muitas vezes, existem alguns determinantes impedindo-as de sair desse ambiente violento. É necessário agir de forma adequada para a solução do caso, sem causar maiores prejuízos à vítima, levando-se em consideração os direitos das mulheres conquistados e registrados em legislação.

Esse tema começou a ganhar espaço no cenário brasileiro quando começaram a emergir problemas relacionados à saúde da mulher, sendo eles: abortos, infecções sexualmente transmissíveis e gravidez indesejada. A partir disso, o país ratificou a Convenção sobre a Eliminação de Todas as Formas de Discriminação da Mulher (CEDAW) (ONU, 1994) e passou a participar da defesa dos direitos da mulher de forma mais ativa. Além disso, com o desígnio de resolver esses problemas, em 1981 o Ministério da Saúde brasileiro criou o Programa de Assistência Integral à Saúde da Mulher (PAISM), porém, objetivando apenas a saúde reprodutiva da mulher (BRASIL, 2004).

Em 1985, houve a implantação do Conselho Nacional dos Direitos da Mulher (CNDM) e a primeira Delegacia Especializada de Atendimento à Mulher (DEAM) no Brasil. Esses dispositivos foram importantes, muito embora essa questão, para o estado brasileiro, fosse vista apenas sob o ponto de vista da justiça e da segurança pública (SANTOS; MARQUES, 2014). Com a promulgação da Constituição Federal de 1988, algumas mudanças ocorreram no papel social das brasileiras, como a palavra cidadão, a qual fazia referência apenas ao homem e, a partir de então, passou a incluir as mulheres e os novos direitos fundamentais, como o direito à vida, à igualdade, a não discriminação, à segurança e à propriedade, a fim de possibilitar a igualdade de gênero (SANTOS, 2014).

Em 1995, o Brasil passou a fazer parte da CEDAW de Belém do Pará, que consistiu a Convenção Interamericana, um tratado entre os países da América, com o objetivo de prevenir, punir e erradicar a violência contra a mulher. O tratado estabeleceu, em seu capítulo II, artigos que permitiam às mulheres o direito à liberdade e à igualdade (PINAFI, 2012). 
A procura por mulheres vítimas de violência por serviços de proteção aumentou e, a partir disso, o governo brasileiro homologou a Lei $\mathrm{n}^{\circ} 10.778 / 2003$, que tornou obrigatória a notificação de todos os casos de violência contra a mulher, assistidos em serviços de saúde, público ou privado, dentro do território nacional (BRASIL, 2003). Essa lei representa o marco inicial da violência contra a mulher como um problema de saúde pública, devido aos danos ou sofrimento físico, sexual e/ou psicológico causados à mulher.

Sancionada em agosto de 2006, a Lei $\mathrm{n}^{\circ} 11.340 / 2006$, popularmente conhecida como Lei Maria da Penha, triplicou a pena prevista no Código Penal Brasileiro para agressões domésticas contra mulheres e aumentou os mecanismos de proteção à vítima. Além de possibilitar que autores de violência fossem presos em flagrante e extinguir penas alternativas, a lei também estabeleceu medidas preventivas para proteger a mulher em situação de agressão (BRASIL, 2006).

Como reforço à Lei Maria da Penha, foi criada a Central de Atendimento à Mulher Ligue 180, um serviço oferecido pela Secretaria de Serviço para Mulheres (SPM), com o objetivo de receber denúncias ou relatos de violência, reclamações sobre os serviços da rede, bem como orientar as mulheres sobre os seus direitos e sobre a legislação vigente, encaminhando-as para os serviços quando necessário. Esse serviço permitiu que a Lei Maria da Penha fosse cumprida de forma mais homogênea, levando o serviço para mais perto das mulheres, principalmente daquelas com preferência ao anonimato (LIMA et al., 2016).

Nesse sentido, de acordo com o Atlas de Violência (2019), no ano de 2017, o estado de São Paulo respondeu pela menor taxa de homicídios femininos, 2,2 por 100 mil mulheres, seguido pelo Distrito Federal $(2,9)$, Santa Catarina $(3,1)$, Piauí $(3,2)$ e, ainda, Maranhão $(3,6)$ e Minas Gerais $(3,7)$. Em termos de variação, reduções superiores a $10 \%$ ocorreram em seis Unidades da Federação, a saber: Distrito Federal, com redução de 29,7\% na taxa; Mato Grosso do Sul, com redução de 24,6\%; Maranhão, com 20,7\%; Paraíba, com 18,3\%, Tocantins, com 16,6\%, e Mato Grosso, com 12,6\%.

Assim, em 9 de março de 2015, foi sancionada a Lei $\mathrm{n}^{\circ}$ 13.104, que prevê o feminicídio como circunstância qualificadora do crime de homicídio, sendo incluído no rol dos crimes hediondos (BRASIL, 2015). O principal ganho com essa lei foi tornar o feminicídio visível, além de estabelecer punição mais grave para os que cometessem o crime contra a vida (LIMA et al., 2016). A última atualização do Mapa da Violência, em 2017, traz um aumento de aproximadamente 365\% de homicídios, comparado ao ano de 1980 (ATLAS DE VIOLÊNCIA, 2019). 
Aliado a tal fato e aos altos índices de violência de gênero, surgiu a necessidade da realização do estudo "Violência contra mulher: suas raízes históricas e implicações futuras", aprovado pelo Comitê de Ética em Pesquisa em Seres Humanos (CEP), em 2018, com o no de parecer 2.717.127, buscando compreender o processo de violência e sua repercussão na vida da vítima, dentro do cenário de um Centro Educacional de Educação Continuada (CESEC), que abrange adolescentes e adultos. Além de auxiliar no processo de ensino-aprendizagem de jovens adultos, os professores e enfermeiros licenciados acabam se tornando parte da rotina dos/as estudantes, em que são criados vínculos, algo relevante para que o público-alvo tenha confiança em relatar, expor acontecimentos e, muitas vezes, pedir ajuda sobre algum trauma sofrido.

Observa-se que não é fácil a abordagem devido ao tabu da violência inserido na sociedade. Atualmente, debater tal tema ainda deixa muitas mulheres coagidas e com medo, fazendo-se necessário muito diálogo e paciência dos profissionais para entenderem os sinais e deixá-las confortáveis. Por tal fato, o profissional da saúde deve se conscientizar de que cada mulher tem sua forma de agir e de pensar, devendo ser capaz de identificar as fragilidades da mulher, transmitindo confiança, de forma que a mesma se sinta acolhida e segura para expor as situações vivenciadas (MEDINA; PENNA, 2008).

Diante do exposto, o estudo teve como objetivo relatar experiências e promover reflexões sobre violência de gênero, seus tipos, sinais de vulnerabilidade e formas de enfrentamento em um espaço educacional.

\section{Metodologia}

Foi realizada uma palestra no mês de dezembro de 2019 em um Centro Educacional de Educação Continuada. O CESEC é uma escola pública mantida pelo governo de Minas Gerais, que tem como foco a educação na modalidade de ensino semipresencial, inserida em um bairro de Uberlândia-MG, com a proposta de informar os tipos de violência existentes e esclarecer como eles podem ser identificados e denunciados.

Participaram cerca de trinta alunos, com faixa etária entre 15 e 50 anos, sendo a maioria de classe baixa, quatro discentes e um docente da graduação em Enfermagem, tendo a atividade aproximadamente duas horas de duração. O CESEC é uma escola semipresencial que faz parte da Rede Estadual de Ensino, prestando serviços aos jovens e adultos que não concluíram seus estudos na idade de direito. Oferece cursos desenvolvidos em regime 
didático de matrícula por componente curricular (disciplina) ou conjunto de componentes curriculares, incluindo momentos presenciais e não presenciais.

Constituiu-se, inicialmente, pela distribuição de papéis, sendo orientado que os participantes anotassem dúvidas sobre o tema. Logo em seguida, foram realizados breve exposição sobre dados estatísticos em relação à violência sofrida pelas mulheres e esclarecimentos sobre todos os tipos em que ela se configura e que pode ser identificada. Após esse momento, foram executados áudios, gravados pelos próprios discentes, contendo situações do dia-a-dia que se configuram como um tipo de violência. Após cada áudio, questionava-se sobre qual o tipo de violência abordado no áudio reproduzido, havendo uma interação direta com o público. Em seguida, projetou-se um vídeo, que continha ligações de denúncia de mulheres em situação de violência para a polícia militar. Por fim, foi iniciado um debate com o esclarecimento de dúvidas, as quais foram registradas em papel no início da palestra.

A proposta teórico-pedagógica que ancorou a ação foi do tipo problematizadora, a qual vislumbra uma participação, dialógica, crítica, reflexiva e transformadora por parte dos sujeitos envolvidos. Nesse contexto, não existe saber "certo ou errado", verticalizado e orientado pela transmissão de conhecimentos, ao contrário, busca-se a humanização e o compartilhamento de práticas e saberes (FREIRE, 2001; ALVIM, FERREIRA, 2007).

Dessa forma, a experiência relatada foi vivenciada durante a abordagem do assunto "violência contra a mulher", realizada em uma instituição educacional destinada à informação da população acerca da identificação de cenários de violência, formas de resolução, assim como conhecimento de números para denúncia e apoio da vítima. Nesse encontro, foram abordadas, em conjunto com os alunos da instituição, as diversas formas de violência contra a mulher, encorajando discussões sobre situações vivenciadas e oferecendo apoio aos participantes que demonstraram vulnerabilidade, reforçando o empoderamento feminino e a necessidade de apoio à vítima e de denúncia da situação vivenciada.

\section{Resultados e Discussão}

A partir dessa experiência em questão, foram levantados vários pontos de questionamento e reflexão, tanto pelos discentes, após a palestra e discussão quanto pelos próprios participantes, que, de modo geral, foram muito atuantes, manifestaram opiniões, questionamentos, experiências, o que enriqueceu o debate de forma muito surpreendente. 
Como mencionado anteriormente, acerca das diversas formas de violência, muitos participantes levantaram questionamentos sobre as situações de violência em questão, dizendo o quanto elas eram comuns e como eles mesmos já haviam passado ou presenciado um cenário de agressão contra a mulher. Foram mencionados casos vividos que levaram os participantes a refletirem sobre a importância do apoio à mulher e a necessidade de melhora nas formas de denúncia e auxílio. Durante essa reflexão, foram surgindo falas de ausência de coragem para denunciar devido ao pouco caso com que as autoridades tratam as denúncias, levando a mulher a permanecer sofrendo as agressões.

A falta de credibilidade em relação à vítima, o menosprezo a seu relato e o medo do julgamento da comunidade em que ela está inserida podem tornar a mulher alvo de comentários que a inferiorizem e a culpabilizem pela situação vivenciada. Ficou claro que muitos tinham conhecimento da violência vivida, mas justificaram o comportamento do agressor, remetendo-se aos papéis tradicionais entre o casal, ou seja, é predominante as crenças de que cabe sempre à figura feminina compreender as fraquezas do cônjuge e manter a família unida (JONG et al., 2008).

Durante a atividade, seja no decorrer da reprodução dos áudios, da palestra em si ou na apresentação dos dados, foi claramente perceptível nas expressões dos alunos presentes os sentimentos despertados pelas informações mencionadas. Algumas pessoas choraram e, a cada áudio, fala e dado exposto, algumas pessoas davam indícios, por meio de gestos, de já terem passado ou de ainda estarem passando por aquele tipo de problema, o que, no final, se confirmou com os relatos expostos.

Muitos alunos, durante e, principalmente, após o final da palestra, se sentiram confortáveis de tirar dúvidas e expor casos vivenciados por eles. Em diversas falas, foram reconhecidos a indignação por ocorrer esse tipo de situação com familiares ou pessoas próximas, o medo das vítimas de serem julgadas e não ouvidas, o medo de não terem mais uma família completa - que é considerada apenas se os filhos viverem em conjunto com o casal de pais - e o medo de não terem condições de sustentar a casa sem a ajuda do parceiro. Porém, além dos sentimentos de revolta e terror, foram demonstrados sentimentos de suporte, compreensão e empatia para com as mulheres.

Entre os relatos, o discurso de uma participante impactou os palestrantes devido às situações de violência vivenciadas por ela. Após se sentir segura para contar sua história, ela contou aos participantes sobre as agressões sofridas do pai durante a adolescência. Os alunos, em muitos momentos, relataram a experiência de passar por violência física sofrida por 
cuidadores do sexo masculino, principalmente após o consumo de bebidas alcoólicas. Uma delas relatou: "é preciso ter somente um momento de coragem para denunciar".

Observa-se que, após a discussão acerca da dificuldade da denúncia, muitos alunos, em várias ocasiões, cogitaram a possibilidade de denunciar as agressões sofridas, contudo, muitos eram responsáveis por cuidar de seu cuidador e, por esse motivo, nunca conseguiam alcançar esse "momento". Uma participante relatou que só conseguiu resolver a situação quando se casou e mudou de cidade. Contudo, após o casamento, começaram as agressões pelo companheiro, porém, a mesma relatou que decidiu não mais tolerar aquela realidade e o deixou. Nesse momento, percebeu-se o entendimento pelos alunos da importância do tratamento psicológico e do conhecimento sobre seus direitos, pois, como relatou uma pessoa no final, "esse conhecimento que lhe deu força e coragem pra conseguir largar tudo aquilo que a fazia mal para trás e refazer sua vida com sua filha".

Isso expõe a existência da moral conservadora, que ainda subjuga a mulher ao homem, mesmo ela possuindo direitos iguais perante o Código Civil, o que leva a uma subnotificação dos casos de violência, demonstrando uma resistência da sociedade em lidar com situações nos diversos setores, como: judiciário, segurança e saúde. Podemos citar, como exemplo, a banalização do sexo cedido ou forçado no casamento, por ser considerado uma obrigação da mulher dentro da vida conjugal (SOUZA; ADESSE, 2005).

Dados do DataSenado de 2017 revelam que cerca de 27\% das vítimas não tomam atitude contra o perpetrador da agressão (DATASENADO, 2017). Isso ocorre devido ao medo de represália por parte do autor, ao julgamento, à normalização da violência pela sociedade como forma de resolução de conflitos, ao descrédito nas instituições de segurança pública e justiça, entre outros (ANUÁRIO..., 2019).

A participante mencionada acima demonstrou preocupação com o desenvolvimento da filha, que presenciou, diversas vezes, as situações de agressão, pois existe a possibilidade de que, quando adulta, a criança veja cenas de violência como algo normal, o que prejudicaria a busca por ajuda caso, futuramente, viesse a sofrer violência cometida pelo/a parceiro/a. De acordo com Oliveira (2011), apesar de não se ter uma causalidade linear, tem-se determinado que a violência no contexto familiar é um fator de risco confirmado para que, em relações futuras, ocorra a prática de comportamentos violentos ou a situação de ser vítima, sendo isso baseado na Teoria da Aprendizagem Social.

Além disso, foi mencionado pela mãe da criança que, sempre que alguém tentava algum contato com ela, a garota começava a chorar, já evidenciando o medo de sua mãe estar sofrendo algum tipo de agressão novamente, o que demonstra o trauma devido à convivência 
com cenários de violência. Isso deixa claro o quanto a convivência com a violência pode impactar todos os familiares e o quanto pode vir a ser importante trabalhar com todos para que ocorra um melhor enfrentamento da situação e a não reprodução das cenas violentas, quebrando o ciclo de violência que se perpetua de geração para geração (OLIVEIRA, 2011).

Durante a exposição de dados para os participantes, alguns pontos foram destaque para o início de algumas discussões, como a possibilidade de qualquer mulher sofrer agressão, sendo ela de qualquer classe social, cultura ou religião, e, devido a isso, a necessidade de empatia e sororidade entre as mulheres, além do olhar para o outro sem julgamentos, procurando auxiliar e respeitar a mulher, sua história como ator social e, a partir desse ponto, apoiá-la para que consiga, por si mesma, sair da situação de violência em que se encontra.

Nos primórdios da humanidade, a mulher possuiu papel de coadjuvante, mantendo-se apenas como acompanhante do homem. Mesmo estando em uma constante busca pela libertação do estigma de mãe, responsável pelas atividades do lar, ela continua com o estereótipo de dona de casa, sendo julgada fora do comum quando não segue tal padrão. Dessa forma, a estigma do feminino é algo que interfere no papel da mulher dentro da sociedade patriarcal, sendo que o gênero feminino não pode se desvincular da imagem já estabelecida de submissão ao homem (PEREIRA et al., 2019).

No decorrer da palestra, os participantes demonstraram, aos poucos, algumas expressões de repulsa, horror, indignação, pena, empatia, entre outros. Assim, ficou evidente que muitos reconheciam as formas de violência expostas, porém, não tinham conhecimento de todas como formas de agressão. Vários participantes foram capazes de reconhecer todas as formas de violência demonstradas, revelando um conhecimento prévio sobre o assunto ou por terem presenciado ou vivenciado alguma forma de agressão, principalmente psicológica. Esta compreendida de maneira distinta por influência da cultura e da construção social e histórica de cada indivíduo e da sociedade. Ou seja, os participantes tinham conhecimento das formas de violência quando foram mostradas, mesmo que de formas diversas, porém, quando foram questionados sobre as formas de denúncia e os órgãos que oferecem ajuda a mulheres que sofrem violência, poucos souberam responder. Além disso, o público expressou reconhecer a carga psicológica que todos carregavam após vivenciar uma situação de violência, ressaltando a negatividade e o trauma que as vítimas são obrigadas a carregar ao longo de sua vida.

Além disso, foi discutido pelos participantes o processo de naturalização da violência, já que diversos indivíduos, ainda que inseridos nesse cenário, não conseguem discernir que estão sendo vítimas, pois consideram normal o parceiro ser autoritário e violento, comportando-se da forma que desejar, pois, culturalmente, o papel do homem é ser o chefe da 
família e o provedor, tendo o controle sobre a vida conjugal. Tudo isso devido à vinculação da imagem da mulher à subordinação, responsável pelo cuidado do lar e dos filhos, sendo sempre culpabilizada pelos erros que ocorrem dentro do âmbito familiar (NÓBREGA et al., 2019).

Tais fatores apontam para padrões formulados pela sociedade patriarcal do papel da mulher e do homem dentro e fora do lar, levando os indivíduos a agirem e se comportarem de acordo com o que é ditado pela cultura dominantemente machista, sendo tais fatores contribuintes à propagação da violência (NÓBREGA et al., 2019).

Além disso, há, atualmente, a reprodução de cenas em que mulheres são tratadas de forma desrespeitosa, humilhante e agressiva como forma de punição, e, geralmente, são mostradas para o público como vilãs, merecedoras desse tipo de tratamento. Dessa forma, o pensamento de que é correto esse tipo de correção agressiva é passado para o público, neutralizando situações de violência, que vão da tela para o ambiente familiar (CAMINHAS, 2019). Portanto, formas de violência são normalizadas ao longo do tempo, sendo remodeladas conforme as relações são vivenciadas, idealizando um significado do que é masculino e feminino, e, assim, neutralizando a violência do agressor (NÓBREGA et al., 2019).

Após a demonstração de todas as formas de violência, foram expostos dados quantitativos reais de mulheres agredidas, por dia, hora e minutos. Muitos ficaram impressionados com o número de casos e disseram não ter consciência da quantidade de mulheres que se encontram em situações de violência, seja ela qual for. Com isso, foi levantado outro ponto de discussão: já que os gráficos só demonstravam os casos de violência denunciados às autoridades, os participantes questionaram sobre os milhões de mulheres que se sentem coagidas a denunciar por diversos fatores, sendo um deles a falta de credibilidade. Relatos de alguns alunos presentes concretizaram o fato de que a maioria dos casos permanece em segredo devido à falta de coragem das vítimas de denunciar seu agressor, por medo de não obterem proteção, tanto para si próprias, quanto para seus filhos e familiares.

Sendo assim, ficou evidente para o público da instituição a necessidade agilidade na resolução dos casos de violência, buscando preservar a mulher e sua família, além da punição, na forma da lei, dos agressores, o que motivaria outras mulheres a denunciarem e buscarem formas de sair do cenário de agressão em que vivem.

\section{Considerações finais}

Tratado como tabu, trazendo sentimentos negativos como culpa e rebaixamento, a violência contra as mulheres emergiu devido à fundamentação cultural das relações de gênero, 
que, comumente, subjuga o sexo feminino, resumindo seu papel ao da procriação e ao cuidado da prole. Tendo como ponto de partida a inferiorização da mulher, foi observada a necessidade da disseminação de dados e informações que empoderem e possibilitem à figura feminina reconhecer e denunciar situações de violência vivenciadas seja como vítima ou não.

Ao explanar o tema proposto, foi possível verificar a falta de informação que os integrantes do grupo possuíam em relação à violência vivida pelas mulheres em variadas ocasiões e, ainda, o temor que tinham em apenas debater sobre o assunto.

As situações de violência propostas revelaram, aos participantes, comoção, ao ponto de quererem contar seus próprios casos, o que levou a uma discussão mais aberta. Foi observada, então, a carência do empoderamento feminino para que haja autonomia e posicionamento frente à sociedade. Com esses recursos, serão capazes de assumir seu papel e local de fala, e, em conjunto com outras mulheres, poderão empenhar-se para a construção de redes de apoio e auxílio, contribuindo para a luta contra a violência de gênero.

Agressão física, sexual, psicológica, econômica e patrimonial foram os tipos de violência contra as mulheres abordados na ação, os quais são considerados recorrentes em uniões amorosas, relações em que os participantes reconheceram novas formas que elas podem ocorrer. Estabeleceu-se, então, que a violência de gênero ocorre, principalmente, entre casais com alguma forma de associação, não sendo limitada a determinada comunidade, sendo arquitetada ao longo do tempo com o objetivo de reduzir a mulher na sociedade, tornando-a submissa ao sexo masculino. Ao final da ação, foi possível notar que as informações e os debates levados ao público da instituição gerou impacto significativo na aspiração em transformar a realidade em que vivemos na atual sociedade, ainda que com apreensão em fazê-lo.

Deve-se enfatizar que não é uma ação pontual que sensibiliza as mudanças de conceitos. Para tanto, há necessidade de produzir mais lugares de fala e de desconstruir conceitos oriundos da cultura patriarcal. Assim, necessita-se de mais ações que tragam um reconhecimento desse lugar de poder, igualdade de fato e direito, não somente para o públicoalvo da ação, mas também para os profissionais que fazem essas ações, como na instituição de referência.

Assim, a ação proporcionou ponderar sobre como proceder ao lidar com indivíduos que presenciaram aquela realidade e proporcionou procurar a melhor maneira de intervir em sua saúde física e mental, entendendo, também, como profissionais lidam e empoderam esses diálogos nesses locais. 


\section{Referências}

ALVIM, N. A. T.; FERREIRA, M. A. Perspectiva problematizadora da educação popular em saúde e a enfermagem. Texto contexto - enferm., Florianópolis, v. 16, n. 2, p. 315-319, 2007. DOI: 10.1590/S0104-07072007000200015

ANUÁRIO BRASILEIRO DE SEGURANÇA PÚBLICA. 2019. Disponível em: http://www.forumseguranca.org.br/wp-content/uploads/2019/09/Anuario-2019-FINALv3.pdf. Acesso em: $1^{\circ}$ maio 2020.

ATLAS DA VIOLÊNCIA. 2019. Disponível em: https://www.ipea.gov.br/portal/index.php?option=com_content\&view=article \&id=34784. Acesso em: 10 maio 2019.

BRASIL. Lei $\mathrm{n}^{\circ}$ 10.778, de 24 de novembro de 2003. Estabelece a notificação compulsória, no território nacional, do caso de violência contra a mulher que for atendida em serviços de saúde públicos ou privados. Diário Oficial da União, Brasília, DF, 25 nov. 2003.

BRASIL. Lei $\mathrm{n}^{\circ} 11.340$, de 7 de agosto de 2006. Cria mecanismos para coibir a violência doméstica e familiar contra a mulher, nos termos do $\S 8^{\circ}$ do art. 226 da Constituição Federal, da Convenção sobre a Eliminação de Todas as Formas de Discriminação contra as Mulheres e da Convenção Interamericana para Prevenir, Punir e Erradicar a Violência contra a Mulher; dispõe sobre a criação dos Juizados de Violência Doméstica e Familiar contra a Mulher; altera o Código de Processo Penal, o Código Penal e a Lei de Execução Penal; e dá outras providências. Diário Oficial da União, Brasília, DF, 8 ago. 2006.

BRASIL. Lei n ${ }^{\circ} 13.104$, de 9 de março de 2015. Altera o art. 121 do Decreto-Lei n ${ }^{\circ} 2.848$, de 7 de dezembro de 1940 - Código Penal, para prever o feminicídio como circunstância qualificadora do crime de homicídio, e o art. $1^{\circ}$ da Lei $\mathrm{n}^{\circ} 8.072$, de 25 de julho de 1990, para incluir o feminicídio no rol dos crimes hediondos. Diário Oficial da União, Brasília, DF, 10 mar. 2015.

BRASIL. Ministério da Saúde. Secretaria de Atenção à Saúde. Departamento de Ações Programáticas Estratégicas. Política Nacional de Atenção Integral à Saúde da Mulher: Princípios e Diretrizes. Brasília, DF: MS, 2004. (Série C. Projetos, Programas e Relatórios). Disponível em: http://bvsms.saude.gov.br/bvs/publicacoes/politica_nac_atencao_mulher.pdf. Acesso em: 7 maio 2020.

CAMINHAS, L. R. P. 18 anos da violência de gênero em telenovelas brasileiras: um balanço crítico. In: ENCONTRO ANUAL DA COMPÓS, 28., 2019, Porto Alegre. Anais [...]. Porto Alegre: PUC-RS, 2019.

DATASENADO. Violência doméstica e familiar contra a mulher. 2017. Disponível em: http://www.senado.leg.br/datasenado. Acesso em: $1^{\circ}$ maio 2020.

FREIRE, P. Pedagogia do oprimido. Rio de Janeiro-RJ: Imago, 2001.

JONG, L. C.; SADALA, M. L. A.; TANAKA, A. C. D. Desistindo da denúncia ao agressor: relato de mulheres vítimas de violência doméstica. Rev. esc. enferm. USP, São Paulo, v. 42, n. 4, p. 744-751, dez. 2008. Doi: 10.1590/S0080-62342008000400018. 
LIMA, L. A. A. et al. Marcos e dispositivos legais no combate à violência contra a mulher no Brasil. Rev. Enf. Ref., Coimbra, v. ser IV, n. 11, 2016. Doi: 10.12707/RIV16034.

MAFIOLETTI, T. M. et al. Violência contra mulheres: trajetória histórica de um programa de atenção (Curitiba 1997-2014). REBEN, Brasília, v. 71, n. 6, p. 3081-3089, 2018. Doi: 10.1590/0034-7167-2017-0583.

MEDINA, A. B. C.; PENNA, L. H. G. A percepção de enfermeiras obstétricas acerca da violência intrafamiliar em mulheres grávidas. Texto contexto - enferm., Florianópolis, v. 17, n. 3, p. 466-473. 2008. Doi: 10.1590/S0104-07072008000300007.

NÓBREGA, V. K. M. et al. Renúncia, violência e denúncia: representações sociais do homem agressor sobre a ótica da mulher agredida. Ciênc. Saúde coletiva, Rio de Janeiro, v. 24, n. 7, p. 2659-2666, 2019. Doi: 10.1590/1413-81232018247.16342017.

OLIVEIRA, M. S. A. Violência intergeracional: da violência na família à violência no namoro. 2011. Dissertação (Mestrado em Ciências Forenses) - Faculdade de Medicina, Universidade do Porto, Porto, 2011.

ONU. Organização das Nações Unidas. Convenção sobre a eliminação de todas as formas de discriminação contra as mulheres. Diário do Congresso Nacional, 23 jun. 1994. Disponível em: http://www.onumulheres.org.br/wpcontent/uploads/2013/03/convencao_cedaw1.pdf. Acesso em: 7 mai. 2020.

PEREIRA, G. F. et al. Influência da estrutura patriarcal na construção da emancipação feminina na sociedade contemporânea. In: SEMANA DE MOBILIZAÇÃO CIENTÍFICA (SEMOC), 22., 2019, Salvador. Anais [...]. Salvador: USCAL, 2019.

PIEROTTI, C. F.; D’OLIVEIRA, A. F. P. L.; TERRA, M. F. A situação de violência doméstica de gênero na atenção primário à saúde. Arquivos Médicos, São Paulo, v. 63, n. 1, p. 12-18, 2018. Doi: 10.26432/1809-3019.2018.63.1.12.

PINAFI, T. Violência contra a mulher: políticas públicas e medidas protetivas na contemporaneidade. 2012. Disponível em:

http://www.historica.arquivoestado.sp.gov.br/materias/anteriores/edicao21/materia03/texto03. pdf. Acesso em: 7 mai. 2020.

SANTOS, D. T.; MARQUES, A. D. A convenção sobre a eliminação de todas as formas de discriminação contra as mulheres no Brasil: implicações nas políticas públicas voltadas às mulheres indígenas. Revista Di@logus, Rio de Janeiro, v. 3, n. 1, p. 1-11, 2014. Disponível em: http://revistaeletronica.unicruz.edu.br/index.php/Revista/article/view/1912/433.

Acesso em: 15 maio 2020.

SANTOS, F. L. O dilema jurídico da mulher no Brasil. Sinais: Revista de Ciências Sociais, Vitória-ES, v. 2, n. 1, p. 38-59, 2014. Doi: 10.25067/s.v0i17.10364.

SCOTT, J. Gênero: uma categoria útil de análise histórica. Educação e Realidade, Porto Alegre, v. 16, n. 2, p. 5-22, jul./dez., 1995. Disponível em: https://seer.ufrgs.br/index.php/educacaoerealidade/article/view/71721. Acesso em: 10 maio 2020. 
SOUZA, C. M.; ADESSE, L. Violência sexual no Brasil: perspectivas e desafios. Brasília, DF: SPM, 2005.

ZANATTA, M. A.; FARIA, J. P. Violência contra a mulher e desigualdade de gênero na estrutura da sociedade: da superação dos signos pela ótica das relações de poder. Revista de

Gênero, Sexualidade e Direito, Salvador, v. 4, n. 1, p. 99-114, jan.-jun., 2018. Doi:

10.26668/2525-9849/Index_Law_Journals/2018.v4i1.4209.

Submetido em $1^{\circ}$ de abril de 2020.

Aprovado em 12 de junho de 2020. 